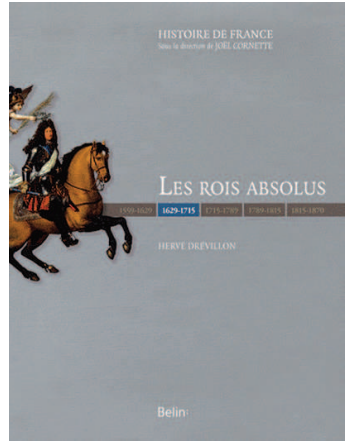

Paulina Grobelna

(Poznań)

\section{ABSOLUTYZM FRANCUSKI Z NOWEJ PERSPEKTYWY}

DOI 10.14746/SEG.2014.9.21

Hervé Drévillon, Les rois absolus (1629-1715), Belin, Paris 2011, $637 \mathrm{~s}$.

W 2009 roku w renomowanym francuskim wydawnictwie Belin ukazał się pierwszy z trzynastu tomów przygotowywanej pod redakcją Joëla Cornette’a „Collection l'Histoire de France". Samo nazwisko pomysłodawcy i głównego koordynatora, uznanego we Francji autorytetu w badaniach nad ancien régimeem, oraz pozostałych autorów poszczególnych części wspomnianej serii zwracają uwagę czytelnika. "Collection l'Histoire de France", której wszystkie trzynaście tomów jest już dostępnych na francuskim rynku wydawniczym, pod wieloma względami wydaje się nietypowa i odbiegająca od powszechnie przyjętych dla publikacji tego typu standardów. Na czym polega jej wyjątkowość? Do kwestii tej jeszcze nie raz powrócimy. „Les rois absolus (1629-1715)” autorstwa Hervé Drévillona, tom siódmy prezentowanej serii, stanowi właściwy przedmiot niniejszej recenzji. H. Drévillon, badacz-historyk związany z Uniwersytetem Paris I Panthéon-Sorbonne, specjalista z zakresu nowożytnej historii militarnej, pierwsze lata swojej pracy naukowej poświęcił zgłębianiu francuskiej literatury astrologicznej siedemnastego stulecia, czego owocem była napisana pod kierownictwem Emmanuela Le Roy Laduriego rozprawa doktorska „Lire et écrire l’avenir. L’astrologie dans la France du Grand-Siècle (1610-1715)”'. Uznanie przyniosły mu jednak przede wszystkim późniejsze prace: „Croiser le fer: violence et culture de l'epée dans la France moderne: XVI $-X V I I^{e}$ siècle” oraz „Limpôt du sang. Le métier des armes sous Louis XIV"2 — źródła wykorzystywanych przez niego w „Les rois absolus (1629-1715)” perspektyw badawczych.

Ujęcie chronologiczno-problemowe, które proponuje autor, jest niezwykle przemyślane. Cała książka, co jest cechą wspólną wszystkich składowych „Collection

${ }^{1}$ H. Drévillon, Lire et écrire l’avenir. Lastrologie dans la France du Grand-Siècle (1610-1715), Seyssel 1996.

${ }^{2}$ Idem, Croiser le fer: violence et culture de l'epée dans la France moderne: XVI ${ }^{\mathrm{e}}-\mathrm{XVII}{ }^{\mathrm{e}}$ siècle, Seyssel 2002; idem, L'impôt du sang. Le métier des armes sous Louis XIV, Paris 2005. 
l'Histoire de France", podzielona została na dwie części: tę właściwą — stricte opisową oraz drugą o znamiennym tytule „Atelier de l'historien” („Warsztat badacza” - tłum. P.G). Narracja historyczna przebiega w dwóch, logicznie wyznaczonych okresach (1629-1661 oraz 1661-1715), których cezury wyznaczają istotne wydarzenia nowożytnej historii Francji: 1629 - pokój w Alais, 1661 - początek samodzielnych rządów Ludwika XIV oraz 1715 - śmierć Króla Słońce.

Leitmotiv omawianej pozycji stanowi wprowadzony jeszcze przez Richelieu i udoskonalany pod rządami Ludwika XIV tzw. system nadzwyczajny (système de l'Extraordinaire). System ten, określany przez badaczy jako zbiór metod i procesów, wprowadzanych w celu wzmocnienia absolutystycznej władzy monarszej przez podporządkowanie jej wszystkich możliwych dziedzin życia społecznego i publicznego, realizowany był za pośrednictwem nowych form systematycznie rozbudowywanej administracji państwowej (podatki, urzędy intendentów, nadzwyczajne sądy, policja itp.). Stopniowe zwiększanie kontroli stwarzało możliwość angażowania większej ilości zasobów państwowych na cele wojenne, a nadmierna ich eksploatacja prowadziła do niepokojów społecznych.

Podporządkowywanie państwa reżimowi nadzwyczajnemu nie przebiegało $\mathrm{w}$ takim samym stopniu w każdym ze wspomnianych obszarów funkcjonowania państwa. Opór społeczeństwa, którego chyba najbardziej znanym przejawem była przypadająca na lata 1648-1653 Fronda, był tylko jednym z wielu czynników, stojących na drodze władzy absolutystycznej. Relacje państwo - Kościół, sprzedawalność urzędów (paulette), system fisco-financier, i inne, omówione w osobnych rozdziałach i podrozdziałach, w doskonały i zrozumiały sposób ilustrują funkcjonowanie państwa Ludwików XIII i XIV.

Ogromnym atutem omawianej publikacji (jak i całej serii) jest jej aktualność historiograficzna. Zorientowanie autora w literaturze i znajomość najnowszych wyników prowadzonych badań zaowocowały zupełnie nowym spojrzeniem na wiele kwestii, podanym w przystępny sposób szerokiemu gronu czytelników. „Collection l'Histoire de France", skierowana przede wszystkim do amatorów, wzbudza zainteresowanie również wśród doświadczonych badaczy. Klasyczny obraz narracji historycznej zaprezentowany w pierwszej części tomu uzupełniony został w drugiej części „Warsztatem badacza”. Jest to niewątpliwie kolejna zaleta „Les rois absolus (1629-1715)". Ukazując złożoność podejmowanej problematyki, autor nie unika stawiania trudnych pytań. Ilustracją zastosowanych metod i prezentowanych wyników są obszerne fragmenty tekstów źródłowych, stanowiące również cechę charakterystyczną omawianej publikacji.

O pewnej nietypowości podejścia autora do omawianej problematyki świadczy również sposób przedstawienia zamku królów Francji w Wersalu. Ukazany przez 
autora wyłącznie za pomocą barwnych ilustracji ogrodów, wnętrz, w tym również poszczególnych elementów plafonu Galerii Lustrzanej oraz, raczej nieznanej w Polsce, przedrukowanej w całości instrukcji zwiedzania Ogrodu Wersalskiego, sytuuje czytelnika w samym środku symboli i propagandy absolutyzmu Króla Słońce, unaoczniając wielorakość sposobów, na jakie można czytać i rozumieć Wersal.

Na uwagę zasługuje także szata graficzna całej serii. Przedmiotem niniejszej recenzji jest wydanie kolekcjonerskie jednego z jej tomów (droższe, lepiej oprawione), jednak tym, co zdecydowanie wyróżnia „Collection l'Histoire de France” jest bogactwo źródeł ikonograficznych, map, wykresów (mówi się o 200 ilustracjach w każdym tomie) dokładnie skatalogowanych i opisanych na końcu książki. W podobny sposób potraktowano źródła, których szczegółowy wykaz, ze względu na pozbawienie publikacji klasycznego aparatu krytycznego, umieszczono w bogatych aneksach (obok tablic genealogicznych, indeksu osób etc.).

Niezwykle obszerna i, co najważniejsze, aktualna bibliografia to kolejny walor omawianej publikacji. Jej znajomość potwierdza autor niemal na każdej stronie swojego dzieła. Zaznaczony powyżej brak aparatu krytycznego — zrozumiały dla publikacji tego typu — nie stanowi problemu dla badaczy bardziej zorientowanych w literaturze, może być jednak sporym utrudnieniem dla czytelników-amatorów lub dla początkujących badaczy, poszukujących ewentualnych wskazówek bibliograficznych. Dobrym rozwiązaniem byłoby umieszczenie bibliografii na końcu każdego $\mathrm{z}$ rozdziałów, ponieważ poruszanie się $\mathrm{w}$ tak obszernym materiale $\mathrm{w}$ formie, $\mathrm{w}$ jakiej został on umieszczony na końcu tomu (spis alfabetyczny), może być dla niewprawionych niezwykle trudne. Jest to jednak drobny mankament, niewpływający negatywnie na ogólną — zdecydowanie pozytywną — ocenę pracy.

„Les rois absolus (1629-1715)”, jak cała „Collection l'Histoire de France”, jest dziełem przełamującym pewne zastane już stereotypy dotyczące nie tylko dziejów Francji, ale również historii jako dyscypliny badawczej. Stanowi pewnego rodzaju wzór, w jaki sposób pisać i rozpowszechniać historię w szerokich kręgach odbiorców, skłaniając ich do własnych poszukiwań i refleksji.

Warto, aby pozycja ta została przetłumaczona na język polski. W naszym środowisku naukowym dominuje w dalszym ciągu nieaktualna już opinia na temat absolutyzmu oraz Francji pod panowaniem dynastii Burbonów, zwłaszcza zaś Ludwika XIV, przełamywana raz po raz pojedynczymi głosami sygnalizującymi fakt, że nie do końca mogło być tak, jak przyjęliśmy sądzić (Jan Baszkiewicz ${ }^{3}$, Maciej

\footnotetext{
${ }^{3}$ J. Baszkiewicz, Francuski absolutyzm XVII stulecia, [w:] A. Mączak (red.), Europa i świat w początkach epoki nowożytnej, 2: Ideologie, kryzysy, konflikty, Warszawa 1992, s. 219-252.
} 
Serwański $\left.{ }^{4}\right)$. Prezentowane w „Les rois absolus (1629-1715)” ustalenia stanowią rezultat prowadzonych od lat osiemdziesiątych ubiegłego stulecia badań nad absolutyzmem, których efektem było odejście od powszechnie przyjętej lavissowskiej koncepcji absolutyzmu francuskiego, utrwalanej jeszcze dziś w podręcznikach szkolnych i akademickich ${ }^{5}$. Mnogość poglądów nie daje jednoznacznej odpowiedzi na pytanie, jaki w istocie był absolutyzm Króla Słońce, najwybitniejszego przedstawiciela, dziedzica i jednocześnie twórcy tej formy sprawowania rządów. Coraz częściej mówi się o współpracy króla z parlamentami ${ }^{6}$ oraz królu - marionetce w rękach swoich głównych doradców ${ }^{7}$, wskazując jednocześnie na inne niewydolności systemu, tak mocno utożsamianego w naszej świadomości z silną i skuteczną władzą monarszą. Książka Hervé Drévillona mogłaby stanowić impuls do podejmowania dalszych badań $\mathrm{z}$ tej dziedziny, stanowiących doskonałe uzupełnienie dotychczasowej, ogromnej pracy badawczej z zakresu stosunków polsko-francuskich oraz przyczynek do weryfikacji poglądów utrwalonych przez lata w naszej historiografii.

Wartościowe poznawczo byłoby również przetłumaczenie całej serii. Na pewno rzuciłaby nowe światło na klasyczną już „Historię Francji” J. Baszkiewicza ${ }^{8}$, z którego ustaleniami nikt do tej pory w Polsce nie podjął szerszej dyskusji merytorycznej.

\footnotetext{
${ }^{4}$ M. Serwański, Czy Francja Ludwika XIV była monarchią absolutną?, [w:] J. Dobosz, D. Konieczka-Śliwińska (red.), Powtórka przed... III spotkania z historią dla uczniów szkół ponadgimnazjalnych, Poznań 2001, s. 41-52.

${ }^{5}$ J. Cornette, L'histoire au travail. Le nouveau "Siècle de Louis XIV”: un bilan historiographique depuis vingt ans (1980-2000), Histoire, Économie et Société 19, 4, 2000, s. 561.

${ }^{6} \mathrm{O}$. Chaline (red.), Les parlements de Louis XIV: opposition, cooperation, autonomisation? Actes de colloque de Rennes, 13-15 novembre 2008, passim.

${ }^{7}$ D. Dessert, Le Royaume de Monsieur Colbert (1661-1683), Paris 2007, passim.

${ }^{8}$ J. Baszkiewicz, Historia Francji, Wrocław 1999.
} 